\title{
Individual patients hold different beliefs to prescription medications to which they persist vs nonpersist and persist vs nonfulfill
}

This article was published in the following Dove Press journal:

Patient Preference and Adherence

24 June 2010

Number of times this article has been viewed

\section{Colleen A McHorney Abhijit S Gadkari}

U.S. Outcomes Research, Merck and Co. Inc., North Wales, PA, USA
Correspondence: Colleen A McHorney U.S. Outcomes Research,

Merck and Co., Inc., 35I North

Sumneytown Pike, UG2MW-05,

North Wales, PA 19454, USA

Tel +l 2673052425

Fax + I 2673050860

Email colleen_mchorney@merck.com
Objective: Our objective was to explore whether adults hold different beliefs about medications to which they persist vs nonpersist and persist vs nonfulfull.

Methods: We conducted a cross-sectional survey of adults with asthma, hypertension, diabetes, hyperlipidemia, osteoporosis, or other cardiovascular disease from the Harris Interactive Chronic Illness Panel. A quota was set to obtain a sample of respondents who were persistent to a medication for one disease and nonpersistent or nonfulfilling to a medication for a second, different disease. Respondents completed 32 items yielding five multi-item scales: perceived need for medication ( $\mathrm{k}=12)$, side-effect concerns $(\mathrm{k}=5)$, medication-safety concerns $(\mathrm{k}=5)$, perceived disease severity $(\mathrm{k}=3)$, and knowledge about the prescribed medication $(\mathrm{k}=7)$. Respondents completed the 32 items twice - once for their persistent medication and a second time for their nonpersistent or nonfulfilling medication. Paired sample $t$-tests (bivariate) and generalized estimating equations (GEE) models (multivariate) were used to test the study hypotheses.

Results: Overall, 178 respondents were sampled for being persistent to one medication and nonpersistent to another, while 48 respondents were persistent to one medication and nonfulfilling to a second. For the medication to which an individual patient was persistent vs nonpersistent, there was significantly higher perceived need, fewer side-effect concerns, higher perceived disease severity, and better knowledge about the medication. For the medication to which an individual patient was persistent vs nonfulfilling, there was significantly higher perceived need, fewer side-effect concerns, and better knowledge about the medication.

Conclusion: Individual patients hold different beliefs about medications to which they persist vs nonpersist or nonfulfill. Patients exhibit different medication-taking behaviors for different medications because they weigh the perceived risks and benefits for each medication separately. These results suggest that adherence interventions should be tailored to patients' beliefs about specific medications.

Keywords: adherence, persistence with therapy, medication beliefs, chronic disease, primary nonadherence, medication nonfulfilment

\section{Introduction}

Prescription medications are an essential pillar of primary and specialty care with $70 \%$ of ambulatory visits involving a provided, prescribed, or continued medication. ${ }^{1}$ Nonadherence to prescription medications is a problem of international importance that knows no demographic, geographic, or political boundaries. A recent systematic review reported that, across 79 studies, approximately $16 \%$ of patients fail to fill a new prescription (otherwise known as primary nonadherence or medication nonfulfillment). ${ }^{2}$ Approximately one half of patients who fill a new prescription stop taking their medication in the first year of therapy (otherwise known as medication nonpersistence). ${ }^{3}$ 
Three key adherence 'myth busters' have emerged from five decades of adherence research. First, there are very weak associations between sociodemographic characteristics and adherence. ${ }^{4,5}$ In a seminal meta-analysis, DiMatteo ${ }^{5}$ found the average correlation between adherence and age and gender to be zero and the average correlation between adherence and education and income to be less than 0.10 . Second, across ${ }^{6}$ and within ${ }^{6-10}$ chronic diseases, there is weak correspondence between medication adherence and adherence to lifestyle and self-care recommendations. Third, many researchers have dismissed the plausibility of an 'adherent personality.' ${ }^{11-14}$ Hevey ${ }^{14}$ asserts that 'there is little evidence of personality traits influencing adherence and the search for the "nonadherent" personality type has provided limited insight.' These three findings have gone far towards redirecting research away from trait characteristics and toward patients' mutable characteristics, ie, their beliefs about their treatment and their disease.

Conceptual work has described adherence as a reasoned decision ${ }^{15,16}$ and has explained how patients differentially value different medications. ${ }^{16,17}$ Qualitative research has shed light on how medication taking is a decision-making process and has illustrated how patients balance their concerns about medications against their perceived need for the therapy and its perceived benefits. ${ }^{13,15,18-24}$ Quantitative research has documented that patient beliefs about their treatment, condition, and prognosis, as well as their objective experiences with their treatment, differentiate adherers from nonadherers. ${ }^{25-38}$

If adherence is not a trait characteristic, it stands to reason that individual patients should exhibit different adherence patterns to different medications because they make decisions for each medication according to their beliefs as well as to the information they possess about the medication and the condition. Thus, adherence should represent shades of grey - individual patients can be persistent to some medications, nonpersistent to others, and fail to fill others because they make separate decisions about each medication. Research has indeed demonstrated that individual patients have distinct adherence patterns to assorted medications. ${ }^{30,39-53}$ For example, Chapman ${ }^{41,49}$ reported differential persistence to concomitant antihypertensive and lipid-lowering therapy, and Piette ${ }^{48}$ found differential persistence to antihyperglycemic, antihypertensive, and antipsychotic medications. Research has also shown that individual patients attach differential worth and value to different medications s $^{13,34,54}$ and have diverse beliefs for different medications in regard to their perceived importance, effectiveness, safety, and expected benefits. ${ }^{13,55,56}$ For example, Aikens and Piette ${ }^{56}$ demonstrated that patients prescribed both antihyperglycemic and antihypertensive medications rated the former as more necessary to them; the antihyperglycemic medications also induced more medication concerns than did the antihypertensive medications. Finally, quantitative research has shown that patients with different adherence behaviors have different beliefs about their medications and conditions. ${ }^{30,36,38,57,58}$ In one study, there was a striking distinction between self-reported medication persisters and nonpersisters on 14 different proximal and intermediate adherence drivers..$^{38}$

Despite the totality of this research, we know of no published studies that show different belief structures within individual patients who exhibit different medication-taking behaviors for different medications for different chronic diseases. Herein we report a small study of: (1) 178 patients who reported being persistent to one medication for one chronic disease and nonpersistent to a different medication for a second chronic disease; and (2) 48 patients who reported being persistent to one medication for one chronic disease and not filling a different medication for a second chronic disease.

\section{Methods \\ Study design}

\section{Sampling procedure}

As described in detail elsewhere, ${ }^{38}$ survey participants were selected from the Harris Interactive Chronic Illness Panel (CIP), a nationally-representative, Internet-based panel of hundreds of thousands of adults with chronic disease. Respondents were eligible for the survey if they were aged 40 and older, resided in the U.S., and reported having at least one of six chronic diseases prevalent among U.S. adults: asthma, diabetes, hyperlipidemia, hypertension, osteoporosis, or other cardiovascular disease. Panel members responding to an email invitation were instructed to read the informed consent form and click on yes if they agreed to participate. The protocol for the survey was approved by the Essex IRB.

Three groups of respondents were identified based on their medication-taking behavior: self-reported persisters, self-reported nonpersisters, and self-reported nonfulfillers to prescription medications. Of the 1,283 respondents to the survey, 1,072 were sampled for a single medicationtaking behavior while 226 were sampled for more than one medication-taking behavior (ie, persistent to a medication for one disease and nonpersistent to a medication for a different disease [ $n=178]$; persistent to a medication for one disease and nonfulfilling to a medication for a different disease $[n=48])$. These latter sample members $(n=226)$ are used in the analyses reported herein. 


\section{Definition of medication persisters, nonpersisters, and nonfulfillers}

During the screening portion of the survey, panel members' chronic disease status was reconfirmed. The screener solicited the number of medications respondents currently took for each disease as well as the length of time they reported they had been continuously taking the medication. These items were used to classify respondents as currently persistent to their medication. To identify respondents as nonpersisters, the survey asked if, in the last year, they had stopped taking a prescription medication for one of the six conditions without their providers telling them to do so. To identify respondents as nonfulfillers, the survey asked if, in the last year, they had received, but did not fill, a new prescription from their provider for one of the six target conditions.

\section{Survey content}

The 226 respondents sampled for more than one medication-taking behavior completed a core set of questions on demographics (including age, gender, education, income, and race) and self-reported health. The 226 respondents also completed two identical sets of 32 questions assessing perceived need for medication $(\mathrm{k}=12)$, side-effect concerns $(\mathrm{k}=5)$, medication-safety concerns $(\mathrm{k}=5)$, perceived disease severity $(\mathrm{k}=3)$, and knowledge about the prescribed medication $(\mathrm{k}=7)$. Respondents completed each of the 32 items twice: once for each of the two medications for which they self-reported different medication-taking behaviors. As described in detail elsewhere ${ }^{38}$ multi-item scales were created by summing raw items into a scale score and linearly transforming each sum to a 0-100 metric, with 100 representing the most favorable belief (highest perceived need, fewest side-effect concerns, fewest medication-safety concerns, highest perceived disease severity, and best knowledge), 0 the least favorable, and scores in between representing the percentage of the total possible score. ${ }^{38}$ The multi-item scales were internally consistent, with Cronbach's alpha coefficients ranging from $0.76-0.96$ (median of 0.87 ). ${ }^{38}$

\section{Statistical analysis}

It was hypothesized that respondents would express statistically-different beliefs about the different medications to which they showed (1) persistence vs nonpersistence and (2) persistence vs nonfulfillment. Paired sample $t$-tests and generalized estimating equations (GEE) models were used to determine whether patients' scores were significantly different for the different medication-taking behaviors.
Most standard multivariate techniques assume that observations used in an analysis are independent of all others. This assumption is violated if repeated observations are taken within subjects, such as in this study, because such observations tend to be correlated with each other. When faced with such data, researchers must account for the correlation within responses when estimating regression parameters. ${ }^{59}$ Failure to incorporate correlation of responses can lead to incorrect estimation of model parameter estimates; in particular, the standard error can be too small, increasing the likelihood that a parameter is statistically significant when it truly is not.

Generalized estimating equations (GEE) ${ }^{60,61}$ are employed as a means of testing hypotheses regarding the influence of factors on response variables collected within subjects across time. The GEE models in this study were estimated specifying a Gaussian distribution of the dependent variable, an identity link function, and an exchangeable correlation matrix with robust standard errors. The principal independent variable in the GEE models was a dichotomous indicator of whether a person's response for a specific scale was for a medication for which they were persistent or not (either nonpersistent or nonfulfiller). Covariates included patient-level demographics (age, gender, race, education, income, and self-reported health) as well as dummy variables for the diseases groups.

\section{Results Persistent vs nonpersistent}

Table 1 shows the demographic characteristics of the persistent versus nonpersistent sample. Two-thirds of respondents were female and had a mean age of 60 years. A majority of the respondents were white ( $90 \%)$, had better than a high-school education (79\%), and reported their health as being fair or poor $(63 \%)$.

Table 2 reports the results of paired $t$-tests. For four of the five scales, the mean scores for the nonpersistent medication were significantly lower than those for the persistent medication. Side-effect concerns showed the largest difference between persistent and nonpersistent medications (15.6\% lower for nonpersistent medication), followed by perceived need for medications ( $14.5 \%$ lower for nonpersistent medication), perceived disease severity (9.2\% lower for nonpersistent medication), and knowledge (3.6\% lower for nonpersistent medication).

Table 3 shows results of the GEE models. After controlling for several covariates, respondents had significantly lower perceived need, more side-effect concerns, lower perceived disease severity, and less knowledge for the medication to which they were nonpersistent vs persistent. 
Table I Demographic characteristics

\begin{tabular}{|c|c|c|c|c|}
\hline \multirow[t]{2}{*}{ Variable } & \multicolumn{2}{|c|}{$\begin{array}{l}\text { Persistent } \\
\text { versus } \\
\text { nonpersistent } \\
N=178\end{array}$} & \multicolumn{2}{|c|}{$\begin{array}{l}\text { Persistent } \\
\text { versus } \\
\text { nonfulfillment } \\
\mathrm{N}=48\end{array}$} \\
\hline & $\mathbf{N}$ & $\%$ & $\mathbf{N}$ & $\%$ \\
\hline Age, mean (SD) & 59.8 & 10.8 & 63.4 & 10.8 \\
\hline $40-49$ & 37 & $20.8 \%$ & 4 & $8.3 \%$ \\
\hline $50-59$ & 48 & $27.0 \%$ & 13 & $27.1 \%$ \\
\hline $60-69$ & 62 & $34.8 \%$ & 20 & $41.7 \%$ \\
\hline $70-79$ & 24 & $13.5 \%$ & 8 & $16.7 \%$ \\
\hline $80+$ & 7 & $3.9 \%$ & 3 & $6.3 \%$ \\
\hline \multicolumn{5}{|l|}{ Gender } \\
\hline Male & 61 & $34.8 \%$ & 18 & $37.5 \%$ \\
\hline Female & 117 & $65.7 \%$ & 30 & $62.5 \%$ \\
\hline \multicolumn{5}{|l|}{ Education } \\
\hline High school or less & 38 & $21.4 \%$ & 8 & $16.7 \%$ \\
\hline Some college & 74 & $41.6 \%$ & 26 & $54.2 \%$ \\
\hline College degree & 23 & $12.9 \%$ & 5 & $10.4 \%$ \\
\hline Greater than college degree & 43 & $24.2 \%$ & 9 & $18.8 \%$ \\
\hline \multicolumn{5}{|l|}{ Income } \\
\hline$<25 \mathrm{~K}$ & 39 & $24.7 \%$ & 8 & $19.1 \%$ \\
\hline$\geq 25 \mathrm{~K}<50 \mathrm{~K}$ & 46 & $29.1 \%$ & 14 & $33.3 \%$ \\
\hline$\geq 50 \mathrm{~K}<75 \mathrm{~K}$ & 30 & $19.0 \%$ & 7 & $16.7 \%$ \\
\hline$\geq 75 \mathrm{~K}<100 \mathrm{~K}$ & 21 & $13.3 \%$ & 8 & $19.1 \%$ \\
\hline$\geq 100 \mathrm{~K}$ & 22 & $13.9 \%$ & 5 & $11.9 \%$ \\
\hline \multicolumn{5}{|l|}{ Race } \\
\hline White & 158 & $89.8 \%$ & 46 & $95.8 \%$ \\
\hline Black & 5 & $2.8 \%$ & 1 & $2.1 \%$ \\
\hline Hispanic & 4 & $2.3 \%$ & 0 & $0 \%$ \\
\hline Other & 9 & $5.1 \%$ & 1 & $2.1 \%$ \\
\hline \multicolumn{5}{|l|}{ Health } \\
\hline Fair/poor & III & $62.7 \%$ & 23 & $47.9 \%$ \\
\hline Good & 50 & $28.1 \%$ & 21 & $43.8 \%$ \\
\hline Very good/excellent & 17 & $9.6 \%$ & 4 & $8.3 \%$ \\
\hline \multicolumn{5}{|l|}{ Medication $^{\mathrm{a}}$} \\
\hline Hypertension medication & 29 & $16.3 \%$ & 14 & $29.2 \%$ \\
\hline Asthma medication & 85 & $47.8 \%$ & 17 & $35.4 \%$ \\
\hline Diabetes medication & 83 & $46.6 \%$ & 13 & $27.1 \%$ \\
\hline Lipid medication & 56 & $31.5 \%$ & 18 & $37.5 \%$ \\
\hline Osteoporosis & 57 & $32.0 \%$ & 14 & $29.2 \%$ \\
\hline \multicolumn{5}{|l|}{ medication } \\
\hline Other CVD medication & 46 & $25.8 \%$ & 20 & $41.7 \%$ \\
\hline
\end{tabular}

\section{Persistent vs nonfulfillment}

Table 1 shows the demographic characteristics of the persistent versus nonfulfillment sample. Two-thirds of the sampled respondents were female with a mean age of 63 years and a majority were white $(96 \%)$. Almost equal numbers of respondents reported their health as being fair/poor $(48 \%)$ and good (44\%).

Table 2 reports the results of paired sample $t$-tests. Across three of the five scales (perceived need for medications, side-effect concerns, and knowledge), the mean score for the nonfulfilled medication was significantly lower than that for the persistent medication. Side-effect concerns scale showed the largest difference between scores for persistent and nonfulfilled medications (20.2\% lower for nonfulfilled medication), followed by perceived need for medications (17.9\% lower for nonfulfilled medication), and knowledge (6.3\% lower for nonfulfilled medication).

Table 3 shows results of the GEE models. After controlling for several covariates, respondents had significantly less perceived need for medications, more side-effect concerns, and less knowledge for the medication which was not filled compared to the persistent medication.

\section{Discussion}

\section{Interpretation of study findings}

Of the five studied multi-item scales, perceived need for medications and medication concerns best differentiated between individuals who persisted to one medication and stopped taking another, as well as persons who persisted to one medication and failed to fill another. These findings are consistent with past research which has demonstrated that perceived need for medications and medication concerns, variously operationalized, predict medication adherence..$^{25-38}$ Patients' beliefs should be modifiable: negative beliefs - such as medication concerns - could be assuaged, and positive beliefs - such as perceived need for medications - could be reinforced through appropriate information and counseling. Recent research has demonstrated that patients' medication beliefs can be altered through intervention. ${ }^{62-64}$

Perceived disease severity is a key component of the health belief model ${ }^{65}$ - an organizing framework that has been frequently applied in adherence research. Perceived disease severity significantly differentiated persons persistent and nonpersistent to different medications for different diseases but not so for persistent vs nonfulfillment. Some primary research studies ${ }^{45,66,67}$ and one meta-analysis ${ }^{68}$ found perceived disease severity to be related to medication nonpersistence, while other primary research studies have not. ${ }^{69-73}$ We are aware of only one study that related perceived disease severity to medication nonfulfillment, and no significant relationship was found. ${ }^{74}$ We hypothesize that perceived disease severity was a weaker differentiator of different medication-taking behaviors within individuals because it may influence medication decision-making through its direct effect on perceived need for medications and medications concerns, ${ }^{38}$ which is consistent with tenets of the health belief model. ${ }^{75}$ 
Table 2 Results of paired sample $t$-tests

\begin{tabular}{|c|c|c|c|c|c|}
\hline \multicolumn{6}{|c|}{ Persistent versus nonpersistent medications $(\mathbf{N}=\mathbf{1 7 8})$} \\
\hline \multirow[t]{2}{*}{ Multi-item scale } & \multirow{2}{*}{$\begin{array}{l}\text { Persistent } \\
\text { medication } \\
\text { Mean }\end{array}$} & \multirow{2}{*}{$\begin{array}{l}\text { Nonpersistent } \\
\text { medication } \\
\text { Mean }\end{array}$} & \multicolumn{3}{|c|}{ (Persistent) - (Nonpersistent) } \\
\hline & & & Difference (\% lower) & t-score & $P$-value \\
\hline Perceived need for medications & 77.4 & 66.2 & $11.2(14.5 \%)$ & 6.7 & $<0.001$ \\
\hline Side-effect concerns & 68.5 & 57.8 & $10.7(15.6 \%)$ & 6.1 & $<0.001$ \\
\hline Medication-safety concerns & 52.2 & 51.6 & $0.6(1.2 \%)$ & 0.5 & 0.64 \\
\hline Perceived disease severity & 65.3 & 59.3 & $6.0(9.2 \%)$ & 3.1 & $<0.01$ \\
\hline Knowledge about the prescribed medication & 83.1 & 80.1 & $3.0(3.6 \%)$ & 3.0 & $<0.01$ \\
\hline \multicolumn{6}{|c|}{ Persistent versus nonfulfilled medications $(\mathrm{N}=\mathbf{4 8})$} \\
\hline \multirow[t]{2}{*}{ Multi-item scale } & $\begin{array}{l}\text { Persistent } \\
\text { medication }\end{array}$ & $\begin{array}{l}\text { Nonfulfilled } \\
\text { medication }\end{array}$ & \multicolumn{3}{|c|}{ (Persistent) - (Nonfulfilled) } \\
\hline & Mean & Mean & Difference (\% lower) & t-score & $P$-value \\
\hline Perceived need for medications & 79.8 & 65.5 & $14.3(17.9 \%)$ & 3.9 & $<0.001$ \\
\hline Side-effect concerns & 71.3 & 56.9 & $14.4(20.2 \%)$ & 3.9 & $<0.001$ \\
\hline Medication-safety concerns & 53.6 & 53.8 & $-0.2(-0.4 \%)$ & -0.1 & 0.95 \\
\hline Perceived disease severity & 63.7 & 59.4 & $4.3(6.8 \%)$ & 1.3 & 0.21 \\
\hline Knowledge about the prescribed medication & 87.9 & 82.4 & $5.5(6.3 \%)$ & 2.9 & $<0.01$ \\
\hline
\end{tabular}

Medication-related information is a necessary, but not sufficient, condition for effective medication-taking behavior. ${ }^{76}$ Knowledge about the prescribed medication significantly differentiated both nonfulfillers and nonpersisters from persisters. This finding is consistent with past research which has demonstrated that patients desire information about their conditions, ${ }^{77}$ are unaware of the possible clinical sequelae of untreated/uncontrolled chronic disease, ${ }^{78}$ and report significant unmet needs for information about the risks and benefits of their medications. ${ }^{22,23,77,79-81}$ While statistically significant, knowledge was not as strong a differentiator of different medication-taking behaviors as perceived need, side-effect concerns, or disease severity. Knowledge has been hypothesized to indirectly affect medication-taking behaviors through behavioral skills (eg, objective and perceived medication-taking skills as well as adherence self-efficacy), ${ }^{82}$ personal motivation, ${ }^{76}$ and health beliefs (general as well as medication- and disease-specific). ${ }^{38,83}$ Thus, the smaller effects observed for knowledge in this study may be due to its mediating, rather than direct effect, on medication decision-making. Consistent with this interpretation, a recent meta-analysis showed rather small effect sizes for information and educational adherence intervention, ${ }^{84}$ a finding similar to other meta-analyses. ${ }^{85,86}$

The multi-item scale assessing long-term medication safety-concerns was not statistically significant in the bivariate or multivariate analyses. The five items included in the scale measured long-term concerns (eg, worry about building up a tolerance, worry my body will become dependent on the medication). Given the long-term and future focus of the items, it is intuitive that they would have less impact on contemporaneous medication decision-making.

Table 3 GEE models predicting subjects' score on the five multi-item scales

\begin{tabular}{|c|c|c|c|c|}
\hline \multirow[t]{2}{*}{ Multi-item scale } & \multicolumn{2}{|c|}{$\begin{array}{l}\text { Persistent versus nonpersistent } \\
\text { medications }^{\mathrm{a}}(\mathrm{N}=338)^{\mathrm{b}}\end{array}$} & \multicolumn{2}{|c|}{$\begin{array}{l}\text { Persistent versus nonfulfilled } \\
\text { medications }^{\mathrm{a}}(\mathrm{N}=90)^{\mathrm{b}}\end{array}$} \\
\hline & $\begin{array}{l}\text { Coefficient on the } \\
\text { GEE model }\end{array}$ & $P$-value & $\begin{array}{l}\text { Coefficient on the } \\
\text { GEE model }\end{array}$ & $P$-value \\
\hline Perceived need for medications & -10.9 & $<0.001$ & -13.0 & 0.01 \\
\hline Side-effect concerns & -10.7 & $<0.001$ & -14.3 & $<0.001$ \\
\hline Medication-safety concerns & 0.3 & 0.85 & 2.0 & 0.59 \\
\hline Perceived disease severity & -6.1 & $<0.01$ & -2.3 & 0.68 \\
\hline $\begin{array}{l}\text { Knowledge about the } \\
\text { prescribed medication }\end{array}$ & -2.5 & 0.02 & -5.9 & 0.01 \\
\hline
\end{tabular}

Notes: a Reference category: Persistent medication; 'bach subject is included twice in the GEE models, once for the persistent medication and once for their nonpersistent/ nonfulfilled medication; 'Covariates in the GEE models included: age, gender, education, income, race, self-reported health, and index medication therapeutic area. 


\section{Limitations of the study}

Our study is not without limitations. Information on medication-taking behaviors was collected by self report and was not corroborated using external indicators, such as pharmacy claims, refill records, pill counts, or electronic monitoring. However, every direct and indirect method of assessing adherence has its limitations, and none are measured without error. Past research has demonstrated that patients reliably report nonadherence. ${ }^{87-89}$ Thus, we have greater confidence in the classification of nonpersisters and nonfulfillers than the self-reported persisters. Any misclassification of the self-reported persisters would have served to provide lower-bound estimates of the observed findings. We did not sample persons who were persistent to prescription medications for two or more different diseases or who were persistent to two or more medications for the same chronic disease. A natural extension of the results reported herein would be to test whether persons persistent to multiple medications have equivalent beliefs about those medications.

The study involved adults with self-identified chronic disease, and none of the six study conditions were substantiated with medical records. However, a well-defined, chronic disease panel was accessed and the six conditions were reverified using a separate, independent screener than that used to enroll the CIP. Only six conditions were studied, although they are highly prevalent in the U.S. adult population. No psychiatric conditions were studied. It is possible that our results may vary for certain subgroups of patients, such as those based on race/ethnicity. We did not have sufficient sample size within the different ethnic groups to conduct a subgroup analysis.

The use of an internet-based sample excludes persons without regular access to computers or the internet. However, the 'digital divide' has narrowed considerably in the past decade. According to a 2010 PewInternet report, $74 \%$ of Americans aged 18 years and older use the Internet. ${ }^{90}$ Gender differentials in internet use have disappeared.$^{90}$ However, age, racial, education, and income differentials remain, with older persons, those with less income and education, and nonwhite Hispanics being less likely to use the internet. In the larger study from which the present sample was derived, we noted that, compared to the U.S. adult population, the internet-based sample had a slight under-representation of adults with income less than $\$ 25,000$ annually, an over-representation of adults with a college education, and over-representation of Caucasians..$^{38}$ Given that the analysis focused on different medication-taking behaviors within individuals, we have no reason to suspect that these possible sample biases would have confounded the observed results.

We controlled for the moderating effect of income on the relationship between patients' beliefs and their medication-taking behavior. However, we did not have information on patients' out-of-pocket cost associated with the prescribed medications or patients' total cost burden for their medications. Future studies should examine perceived medication affordability with respect to different medication-taking behaviors within individual patients. Finally, given the relatively small sample size $(n=90)$ for the GEE modeling of persistent versus nonfulfilling behavior, we cannot negate the possibility that our estimates may be biased. However, there is no agreement in literature as to what represents a sufficient sample size for GEE models. ${ }^{91}$ Also, the number of clusters (ie, subjects with multiple responses) in our models far exceeds 30 , a common rule of thumb for minimum number of clusters required. ${ }^{92}$

\section{Conclusion}

To the best of the authors' knowledge, the results reported herein are the first to empirically demonstrate that patients have different beliefs about medications for chronic disease to which they persist vs nonpersist and persist vs nonfulfill. Patients exhibit different medication-taking behaviors for different medications because they weigh the perceived risks and benefits for each medication separately.

If adherence is to be improved, then nonfulfillment and nonpersistence needs to be, firstly, recognized and, secondly, intervened upon. Suboptimal prescription-medication beliefs that make patients vulnerable to nonfulfillment and nonpersistence should be addressed relatively early in therapy. At the point of initiating new prescriptions and during routine follow up visits, health care providers can influence patients' nascent medication beliefs by eliciting the patient's perspective of the perceived benefits and risks of therapy. Addressing the risks and benefits of therapy could reinforce positive medication beliefs (such as perceived need for medication) and assuage negative ones (such as medication concerns). Results from two recent meta-analyses support this approach: better physician-patient collaboration ${ }^{93}$ and communication ${ }^{94}$ was significantly associated with better adherence.

The results of our study suggest that health care providers cannot assume equivalent medication-taking behaviors within individual patients. Fulfillment of and persistence with prescribed therapy should be monitored on an individual-medication basis. Our results also suggest that claims-based predictive modeling using historical refill patterns for medications other 
than an index medication of interest are likely to explain a negligible amount of variance in persistence.

The results reported herein support the premise that the next generation of adherence interventions must address patient beliefs about their medications and conditions and not merely focus on reminders, which may only be useful for unintentional nonadherence. This study further demonstrates that, within individual patients, salient beliefs vary across different medication-taking behaviors. This suggests that interventions aimed at improving adherence for patients on multiple chronic medications must be tailored to patients' beliefs about specific medications rather than developed generically.

\section{Disclosure}

Drs McHorney and Gadkari are full-time employees of and own stock in Merck and Co., Inc. This research was funded by Merck and Co., Inc.

\section{References}

1. Raofi S, Schappert S. Medication Therapy in Ambulatory Care: United States, 2003-2004. Washington, DC: National Center for Health Statistics, 2006.

2. Gadkari A, McHorney C. Medication nonfulfillment rates and reasons for nonfulfillment: Narrative systematic review. Clin Ther. 2010;26(3):683-705.

3. Haynes RB, McDonald HP, Garg AX. Helping patients follow prescribed treatment: Clinical applications. JAMA. 2002;288(22):2880-2883.

4. McDonald HP, Garg AX, Haynes RB. Interventions to enhance patient adherence to medication prescriptions: Scientific review. JAMA. 2002;288(22):2868-2879.

5. DiMatteo MR. Variations in patients' adherence to medical recommendations: A quantitative review of 50 years of research. Med Care. 2004;42(3):200-209.

6. Kravitz R, Hays R, Sherbourne CD, et al. Recall of recommendations and adherence to advice among patients with chronic medical conditions. Arch Intern Med. 1993;153(16):1869-1878.

7. Glasgow RE, McCaul KD, Schafer LC. Self-care behaviors and glycemic control in type I diabetes. J Chronic Dis. 1987;40(5):399-412.

8. Hernandez-Ronquillo L, Tellez-Zenteno JF, Garduno-Espinosa J, Gonzalez-Acevez E. Factors associated with therapy noncompliance in type-2 diabetes patients. Salud Publica Mex. 2003;45(3):191-197.

9. Hanko B, Kazmer M, Kumli P, et al. Self-reported medication and lifestyle adherence in Hungarian patients with Type 2 diabetes. Pharm World Sci. 2007;29(2):58-66.

10. Uzun S, Kara B, Yokusoglu M, Arslan F, Yilmaz MB, Karaeren H. The assessment of adherence of hypertensive individuals to treatment and lifestyle change recommendations. Anadolu Kardiyol Derg. 2009;9(2):102-109.

11. Britten N. Does a prescribed treatment match a patient's priorities? BMJ. 2003;327(7419):840.

12. Horne R. Compliance, adherence, and concordance: Implications for asthma treatment. Chest. 2006;130 Suppl 1:65S-72S.

13. Elliott RA, Ross-Degnan D, Adams AS, Safran DG, Soumerai SB. Strategies for coping in a complex world: Adherence behavior among older adults with chronic illness. J Gen Intern Med. 2007;22(6):805-810.

14. Hevey D. Adherence to Health Recommendations. In: Perk J, Mathes P, Gohlke H, et al, editors. Cardiovascular Prevention and Rehabilitation. London, UK: Springer, 2007:293-300.
15. Donovan JL, Blake DR. Patient noncompliance: Deviance or reasoned decision-making? Soc Sci Med. 1992;34(5):507-513.

16. Morris LS, Schulz RM. Medication compliance: The patient's perspective. Clin Ther. 1993;15(3):593-606.

17. DiMatteo MR. Patient adherence to pharmacotherapy: The importance of effective communication. Formulary. 1995;30(10):596-602.

18. Conrad P. The meaning of medications: Another look at compliance. Soc Sci Med. 1985;20(1):29-37.

19. Morgan M, Watkins C. Managing hypertension: Beliefs and responses to medication among cultural groups. Sociol Health Ill. 1988;10(4):561-578.

20. Dowell J, Hudson H. A qualitative study of medication-taking behaviour in primary care. Fam Pract. 1997;14(5):369-375.

21. Benson J, Britten N. Patients' decisions about whether or not to take antihypertensive drugs: Qualitative study. BMJ. 2002;325(7369):873.

22. Nair KM, Levine MA, Lohfeld LH, Gerstein HC. 'I take what I think works for me'. A qualitative study to explore patient perception of diabetes treatment benefits and risks. Can J Clin Pharmacol. 2007;14(2):e251-e259.

23. Gordon K, Smith F, Dhillon S. Effective chronic disease management: Patients' perspectives on medication-related problems. Patient Educ Couns. 2007;65:407-415.

24. Lau E, Papaioannou A, Dolovich L, et al. Patients' adherence to osteoporosis therapy: Exploring the perceptions of postmenopausal women. Can Fam Physician. 2008;54(3):394-402.

25. Horne R, Weinman J. Patients' beliefs about prescribed medicines and their role in adherence to treatment in chronic physical illness. J Psychosom Res. 1999;47(6):555-567.

26. Horne R, Buick D, Fisher M, Leake H, Cooper V, Weinman J. Doubts about necessity and concerns about adverse effects: Identifying the types of beliefs that are associated with nonadherence to HAART. Int J STD AIDS. 2004;15(1):38-44.

27. Phatak HM, Thomas J. Relationships between beliefs about medications and nonadherence to prescribed chronic medications. Ann Pharmacother. 2006;40(10):1737-1742.

28. Horne R, Cooper V, Gellaitry G, Date HL, Fisher M. Patients' perceptions of highly active antiretroviral therapy in relation to treatment uptake and adherence: The utility of the necessity-concerns framework. J Acquir Immune Defic Syndr. 2007;45(3):334-341.

29. Menckeberg TT, Bouvy ML, Bracke M, et al. Beliefs about medicines predict refill adherence to inhaled corticosteroids. J Psychosom Res. 2008;64(1):47-54.

30. Clifford S, Barber N, Horne R. Understanding different beliefs held by adherers, unintentional nonadherers, and intentional nonadherers: Application of the necessity-concerns framework. J Psychosom Res. 2008;64(1):41-46.

31. Aikens JE, Nease DE Jr, Nau DP, Klinkman MS, Schwenk TL. Adherence to maintenance-phase antidepressant medication as a function of patient beliefs about medication. Ann Fam Med. 2005;3(1):23-30.

32. Byrne M, Walsh J, Murphy AW. Secondary prevention of coronary heart disease: Patient beliefs and health-related behaviour. J Psychosom Res. 2005;58(5):403-415.

33. Conn KM, Halterman JS, Fisher SG, Yoos HL, Chin NP, Szilagyi PG. Parental beliefs about medications and medication adherence among urban children with asthma. Ambul Pediatr. 2005;5(5):306-310.

34. Ayalon L, Arean PA, Alvidrez J. Adherence to antidepressant medications in black and Latino elderly patients. Am J Geriatr Psychiatry. 2005;13(7):572-580.

35. Conn KM, Halterman JS, Lynch K, Cabana MD. The impact of parents' medication beliefs on asthma management. Pediatrics. 2007; 120(3):e521-e526.

36. McHorney C, Schousboe J, Cline R, Weiss T. The impact of osteoporosis medication beliefs and side effect experiences on nonadherence to oral bisphosphonates. Curr Med Res Opin. 2007;23(12):3137-3152.

37. Gonzalez JS, Penedo FJ, Llabre MM, et al. Physical symptoms, beliefs about medications, negative mood, and long-term HIV medication adherence. Ann Behav Med. 2007;34(1):46-55. 
38. McHorney C. The Adherence Estimator: A brief, proximal screener for patient propensity to adhere to prescription medications for chronic disease. Curr Med Res Opin. 2009;25(1):215-238.

39. Inui T, Carter W, Pecoraro RE, Pearlman RA, Dohan JJ. Variations in patient compliance with common long-term drugs. Med Care. 1980;28(10):986-993.

40. Goldman DP, Joyce GF, Escarce JJ, et al. Pharmacy benefits and the use of drugs by the chronically ill. JAMA. 2004;291(19):2344-2350.

41. Chapman RH, Benner JS, Petrilla AA, et al. Predictors of adherence with antihypertensive and lipid-lowering therapy. Arch Intern Med. 2005;165(10):1147-1152.

42. Gardner EM, Burman WJ, Maravi ME, Davidson AJ. Selective drug taking during combination antiretroviral therapy in an unselected clinic population. J Acquir Immune Defic Syndr. 2005;40(3):294-300.

43. Ho PM, Spertus JA, Masoudi FA, et al. Impact of medication therapy discontinuation on mortality after myocardial infarction. Arch Intern Med. 2006;166(17):1842-1847.

44. Piette JD, Heisler M, Wagner TH. Medication characteristics beyond cost alone influence decisions to underuse pharmacotherapy in response to financial pressures. J Clin Epidemiol. 2006;59(7):739-746.

45. Bardel A, Wallander MA, Svardsudd K. Factors associated with adherence to drug therapy: A population-based study. Eur J Clin Pharmacol. 2007;63(3):307-314.

46. Kindmalm L, Melander A, Nilsson JL. Refill adherence of antihyperglycaemic drugs related to glucose control (HbAlc) in patients with type 2 diabetes. Acta Diabetol. 2007;44(4):209-213.

47. Krigsman K, Nilsson JL, Ring L. Adherence to multiple drug therapies: Refill adherence to concomitant use of diabetes and asthma/COPD medication. Pharmacoepidemiol Drug Saf. 2007;16(10):1120-1128.

48. Piette JD, Heisler M, Ganoczy D, McCarthy JF, Valenstein M. Differential medication adherence among patients with schizophrenia and comorbid diabetes and hypertension. Psychiatr Serv. 2007;58(2):207-212.

49. Chapman RH, Petrilla AA, Benner JS, Schwartz JS, Tang SS. Predictors of adherence to concomitant antihypertensive and lipid-lowering medications in older adults: A retrospective, cohort study. Drugs Aging. 2008;25(10):885-892.

50. Nichol M, Knight T, Wu J, et al. Transition probabilities and predictors of adherence in a California Medicaid population using antihypertensive and lipid-lowering medications. Value Health. 2009;12(4):554-550.

51. Benner JS, Chapman RH, Petrilla AA, Tang SS, Rosenberg N, Schwartz JS. Association between prescription burden and medication adherence in patients initiating antihypertensive and lipid-lowering therapy. Am J Health Syst Pharm. 2009;66(16):1471-1477.

52. Gardner EM, Sharma S, Peng G, et al. Differential adherence to combination antiretroviral therapy is associated with virological failure with resistance. AIDS. 2008;22(1):75-82.

53. Kurlander JE, Kerr EA, Krein S, Heisler M, Piette JD. Cost-related nonadherence to medications among patients with diabetes and chronic pain: Factors beyond finances. Diabetes Care. 2009;32(12): 2143-2148

54. Lau DT, Briesacher BA, Mercaldo ND, et al. Older patients' perceptions of medication importance and worth: An exploratory pilot study. Drugs Aging. 2008;25(12):1061-1075.

55. Williams AF, Manias E, Walker R. Adherence to multiple, prescribed medications in diabetic kidney disease: A qualitative study of consumers' and health professionals' perspectives. Int J Nurs Stud. 2008;45(12): 1743-1756

56. Aikens JE, Piette JD. Diabetic patients' medication underuse, illness outcomes, and beliefs about antihyperglycemic and antihypertensive treatments. Diabetes Care. 2009;32(1):19-24.

57. Lam F, Stevenson FA, Britten N, Stell IM. Adherence to antibiotics prescribed in an accident and emergency department: the influence of consultation factors. Eur J Emerg Med. 2001;8(3):181-188.

58. Iihara N, Kurosaki Y, Miyoshi C, Takabatake K, Morita S, Hori K. Comparison of individual perceptions of medication costs and benefits between intentional and unintentional medication nonadherence among Japanese patients. Patient Educ Couns. 2008;70(2):292-299.
59. Ballinger $\mathrm{G}$. Using generalized estimating equations for longitudinal data analysis. Organ Res Meth. 2004;7:127-150.

60. Liang K, Zeger SL. Longitudinal data analysis using generalized linear models. Biometrika. 1986;73:13-22.

61. Zeger S, Liang KY. Longitudinal data analysis for discrete and continuous outcomes. Biometrics. 1986;42:121-130.

62. Magadza C, Radloff SE, Srinivas SC. The effect of an educational intervention on patients' knowledge about hypertension, beliefs about medicines, and adherence. Res Social Adm Pharm. 2009;5(4):363-375.

63. Bender BG, Apter A, Bogen DK, et al. Test of an interactive voice response intervention to improve adherence to controller medications in adults with asthma. J Am Board Fam Med. 2010;23(2):159-165.

64. Rickles NM, Svarstad BL, Statz-Paynter JL, Taylor LV, Kobak KA. Improving patient feedback about and outcomes with antidepressant treatment: A study in eight community pharmacies. J Am Pharm Assoc. 2006;46(1):25-32.

65. Rosenstock IM. Patients' compliance with health regimens. JAMA. 1975;234(4):402-403.

66. Nelson EC, Stason WB, Neutra RR, Solomon HS, McArdle PJ. Impact of patient perceptions on compliance with treatment for hypertension. Med Care. 1978;16(11):893-906.

67. De Smet BD, Erickson SR, Kirking DM. Self-reported adherence in patients with asthma. Ann Pharmacother. 2006;40(3):414-420.

68. DiMatteo M, Haskard K, Williams S. Health beliefs, disease severity, and patient adherence: A meta-analysis. Med Care. 2007;45(6):521-528.

69. Kirscht JP, Rosenstock IM. Patient adherence to antihypertensive medical regimens. J Community Health. 1977;3(2):115-114.

70. Nagy V, Wolfe G. Cognitive predictors of compliance in chronic disease patients. Med Care. 1984;22(10):912-921.

71. Brownlee-Duffeck M, Simonds JF, Goldstein D, Kilo C, Hoette S. The role of health beliefs in the regimen adherence and metabolic control of adolescents and adults with diabetes mellitus. J Consult Clin Psychol. 1987;55(2):139-144.

72. Brown CM, Segal R. The effects of health and treatment perceptions on the use of prescribed medication and home remedies among African American and white American hypertensives. Soc Sci Med. 1996;43(6):903-917.

73. Turner AP, Kivlahan DR, Sloan AP, Haselkorn JK. Predicting ongoing adherence to disease modifying therapies in multiple sclerosis: Utility of the health beliefs model. Mult Scler. 2007; 13(9):1146-1152.

74. Fincham JE, Wertheimer AI. Using the health belief model to predict initial drug therapy defaulting. Soc Sci Med. 1985;20(1):101-105.

75. Munro S, Lewin S, Swart T, Volmink J. A review of health behaviour theories: How useful are these for developing interventions to promote long-term medication adherence for TB and HIV/AIDS? BMC Public Health. 2007;7:104

76. Martin L, Haskard-Zolnierek K, Dimatteo M. Health Behavior Change and Treatment Adherence. New York, NY: Oxford University Press, 2010.

77. Bailey BJ, Carney SL, Gillies AH, McColm LM, Smith AJ, Taylor M. Hypertension treatment compliance: What do patients want to know about their medications? Prog Cardiovasc Nurs. 1997;12(4):23-28.

78. Hobbs FD, Erhardt LR, Rycroft C. The From The Heart study: A global survey of patient understanding of cholesterol management and cardiovascular risk, and physician-patient communication. Curr Med Res Opin. 2008;24(5):1267-1278.

79. Gardner ME, Rulien N, McGhan WF, Mead RA. A study of patients' perceived importance of medication information provided by physicians in a health maintenance organization. Drug Intell Clin Pharm. 1988; 22(7-8):596-598.

80. Nair K, Dolovich L, Cassels A, et al. What patients want to know about their medications. Focus group study of patient and clinician perspectives. Can Fam Physician. 2002;48:104-110.

81. Barber N, Parsons J, Clifford S, Darracott R, Horne R. Patients' problems with new medication for chronic conditions. Qual Saf Health Care. 2004;13(3):172-175. 
82. Amico KR, Toro-Alfonso J, Fisher JD. An empirical test of the information, motivation and behavioral skills model of antiretroviral therapy adherence. AIDS Care. 2005;17(6):661-673.

83. Eraker S, Kirscht J, Becker, MH. Understanding and improving patient compliance. Ann Intern Med. 1984;100:258-268.

84. SchedlbauerA, Schroeder K, FaheyT. How can adherence to lipid-lowering medication be improved? A systematic review of randomized controlled trials. Fam Pract. 2007;24(4):380-387.

85. Roter D, Hall J, Merisca R, Nordstrom B, Cretin D, Svarstad B. Effectiveness of interventions to improve patient compliance. Med Care. 1998;36(8):1138-1161.

86. Peterson AM, Takiya L, Finley R. Meta-analysis of trials of interventions to improve medication adherence. Am J Health Syst Pharm. 2003; 60(7):657-665.

87. Haynes RB, Taylor DW, Sackett DL, Gibson ES, Bernholz CD, Mukherjee J. Can simple clinical measurements detect patient noncompliance? Hypertension. 1980;2(6):757-764.

88. Choo PW, Rand CS, Inui TS, et al. Validation of patient reports, automated pharmacy records, and pill counts with electronic monitoring of adherence to antihypertensive therapy. Med Care. 1999;37(9):846-857.
89. Wagner JH, Justice AC, Chesney M, Sinclair G, Weissman S, RodriguezBarradas M. Patient- and provider-reported adherence: Toward a clinically useful approach to measuring antiretroviral adherence. J Clin Epidemiol. 2001;54 Suppl 1:S91-S98.

90. Rainie L. Internet, broadband, and cell phone statistics. [Online]. 2010 [cited 2010 Feb. 15]; Available from: http://www.pewinternet.org/ Reports/2010/Internet-broadband-and-cell-phone-statistics.aspx

91. Ghisletta P, Spini D. An introduction to generalized estimating equations and an application to assess selectivity effects in a longitudinal study on very old individuals. J Educ Behav Stat. 2004;29(4):421-437.

92. Norton E, Bieler G, Ennett S, Zarkin G. Analysis of prevention program effectiveness with clustered data using generalized estimating equations. J Consult Clin Psychol. 1996;64(5):919-926.

93. Arbuthnott A, Sharpe D. The effect of physician-patient collaboration on patient adherence in nonpsychiatric medicine. Patient Educ Couns. 2009;77(1):60-67.

94. Zolnierek KB, Dimatteo MR. Physician communication and patient adherence to treatment: A meta-analysis. Med Care. 2009;47(8):826-834.
Patient Preference and Adherence

\section{Publish your work in this journal}

Patient Preference and Adherence is an international, peer-reviewed, open access journal that focusing on the growing importance of patient preference and adherence throughout the therapeutic continuum. Patient satisfaction, acceptability, quality of life, compliance, persistence and their role in developing new therapeutic modalities and compounds to

\section{Dovepress}

optimize clinical outcomes for existing disease states are major areas of interest. This journal has been accepted for indexing on PubMed Central. The manuscript management system is completely online and includes a very quick and fair peer-review system. Visit http://www.dovepress.com/ testimonials.php to read real quotes from published authors. 